\title{
it-sa 2018 in Nürnberg
}

Vom 9. bis 11. Oktober 2018 dreht sich auf der it-sa alles um die IT Sicherheit.

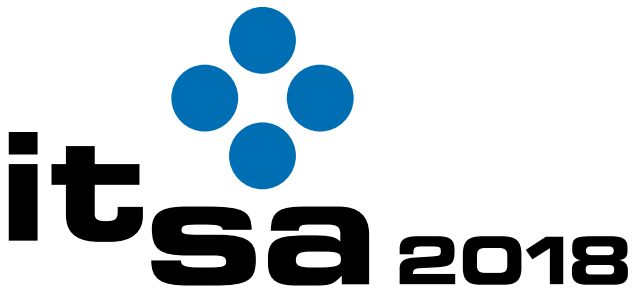

Die IT-Security Messe und Kongress

The IT Security Expo and Congress

Neben Lösungen für IT-Sicherheit und den Top-Themen Cloud Security, Mobile Security, Verschlüsselung, IT Compliance und Biometrie finden auch Basics wie Netzwerksicherheit, Virenschutz oder IT-Grundschutz eine breite Präsentationsfläche. Branchenexperten nutzen die Messe, um sich über die neuesten Produkte und Dienstleistungen zu in- formieren und mit anderen fachlichen Austausch zu pflegen. Besonders gut geht das rund um den Congress@it-sa, auf dem zahlreiche Vorträge zu den unterschiedlichsten Aspekten rund um die IT-Sicherheit gehalten werden.

Im vergangenen Jahr verzeichnete die it-sa 630 Aussteller aus 24 Ländern und konnte über 12000 Fachbesucher aus dem In- und Ausland in Nürnberg begrüßen.

Das Angebotsspektrum der Messe umfasst:

- Produkte und Lösungen für IT-Sicherheit

- Physische IT-Sicherheit

- Dienstleistungen/Beratung/Forschung zur IT-Sicherheit

Entdecken Sie das gesamte Angebotsspektrum unter: https:// www.it-sa.de/de/messeinfo/messeprofil/angebotsspektrum.

Alle Informationen zur Veranstaltung, zu Ticketpreisen, Hotels und Anreise finden Sie unter: https://www.it-sa.de/

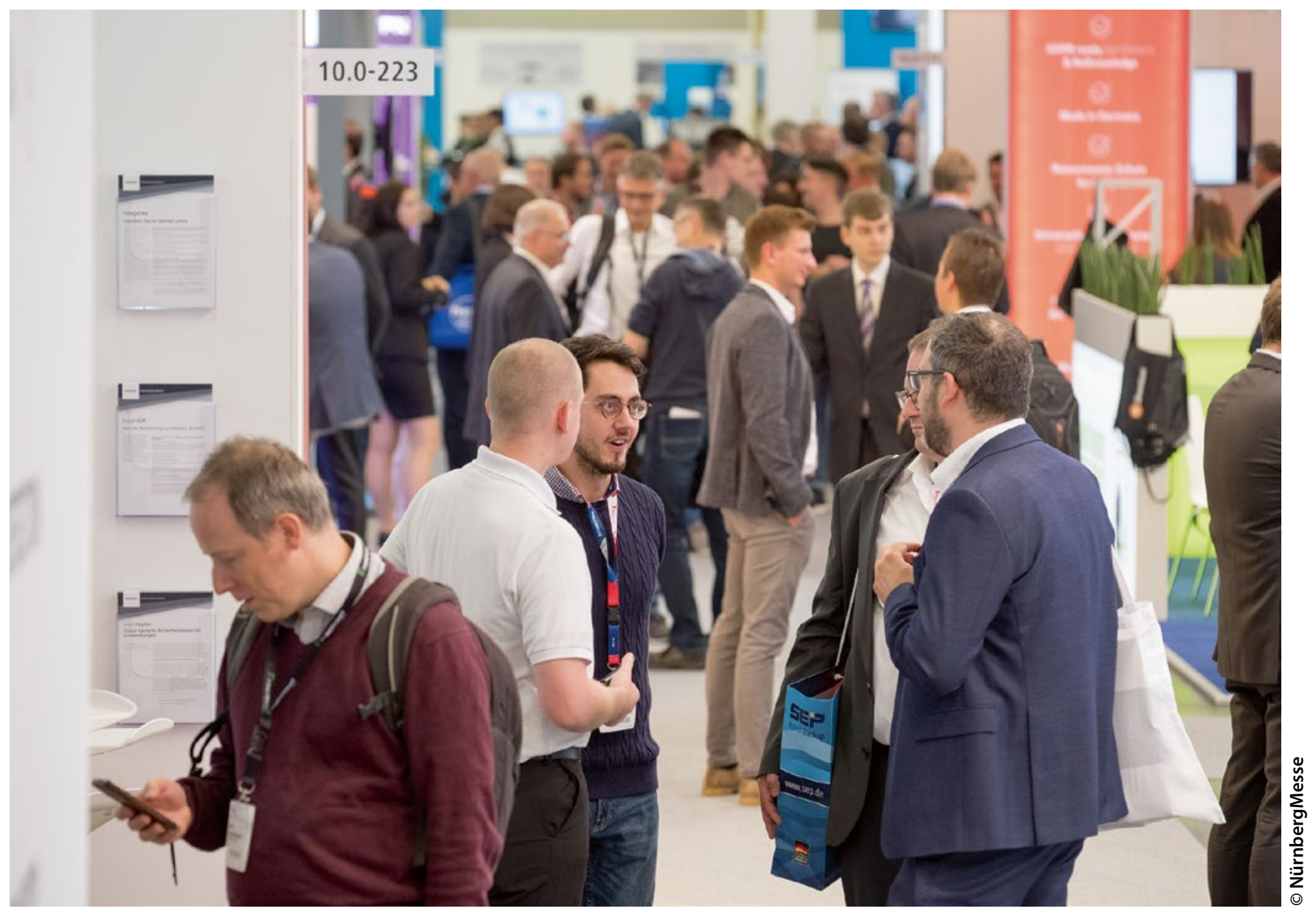

Volle Gänge auf der it-sa 2017. 